\title{
Quantifying the impacts of grassland restoration on biodiversity and ecosystem services in China: A meta-analysis
}

\author{
Yanjiao Ren ${ }^{\mathrm{a}, \mathrm{b}}$, Yihe Lü ${ }^{\mathrm{a}, \mathrm{b}, \mathrm{c}, *}$, Bojie Fu ${ }^{\mathrm{a}, \mathrm{b}, \mathrm{c}}$ \\ a State Key Laboratory of Urban and Regional Ecology Research Center for Eco-Environmental Sciences, Chinese Academy of Sciences, P.O. Box 2871, Beijing \\ 100085, China \\ ${ }^{\mathrm{b}}$ University of Chinese Academy of Sciences, Beijing 100049, China \\ ' Joint Center for Global Change Studies, Beijing 100875, China
}

\section{A R T I C L E I N F O}

\section{Article history:}

Received 7 February 2016

Received in revised form 13 June 2016

Accepted 20 June 2016

Available online 12 July 2016

\section{Keywords:}

Ecological restoration

Biodiversity

Ecosystem services

Grassland

Spatiotemporal variability

Meta-analysis

China

\begin{abstract}
A B S T R A C T
Given the extent of global ecosystem degradation resulting from environmental changes and human activity, restoration efforts have increasingly focused on biodiversity and ecosystem services. Grassland, the largest terrestrial ecosystem globally and in China, has high ecological and economic value. We performed a meta-analysis to assess the impacts of grassland restoration on biodiversity and ecosystem services in China. The results showed that grassland restoration improved biodiversity by $32.44 \%$ and ecosystem services by $30.43 \%$, although the restored grassland from degraded conditions failed to reach the level of non-degraded reference conditions for biodiversity and ecosystem services. The analysis of biodiversity and ecosystem services in the four ecological domains showed significant differences in restored grassland compared to the degraded and reference grassland. Restoration outcomes of biodiversity and ecosystem services were affected by different restoration approaches, but restoration age was not detected as significantly correlated with biodiversity and ecosystem services recovery. Biodiversity recovery, however, was positively correlated with ecosystem services recovery so far in our dataset. Despite this, these patterns require further elucidation and synthetic analyses must be conducted to assess and inform future restoration actions.
\end{abstract}

(c) 2016 Elsevier B.V. All rights reserved.

\section{Introduction}

Climate change, habitat loss, pollution, overexploitation, and invasive species are the main causes of biodiversity loss and ecosystem degeneration, leading to reduced provision of ecosystem services (Butchart et al., 2010; Millennium Ecosystem Assessment, 2005). Ecological restoration, designed to recover and reestablish the characteristics of an ecosystem that have been degraded, damaged, or destroyed, is now recognized as an important strategy to mitigate human pressures on natural ecosystems (Wade et al., 2008). Biodiversity and ecosystem services are two main goals of ecological restoration, which have drawn much attention from international initiatives. These initiatives include the Convention on Biological Diversity (CBD), the Millennium Development Goals (MDGs), the Intergovernmental Science-Policy Platform on Biodiversity and Ecosystem Services (IPBES), Atlantic Forest Restoration

\footnotetext{
* Corresponding author at: State Key Laboratory of Urban and Regional Ecology Research Center for Eco-Environmental Sciences, Chinese Academy of Sciences, P.O. Box 2871, Beijing 100085, China.

E-mail address: lyh@rcees.ac.cn (Y. Lü).
}

Pact, and the development goals of European Union (Calmon et al., 2011; Sachs et al., 2009). Evidence suggests that ecological restoration can enhance biodiversity and provision of ecosystem services (Benayas et al., 2009), but the degree of actual recovery of biodiversity and ecosystem services from those efforts remains uncertain and untested.

Many studies have indicated that increases in biodiversity correlated with enhancement of ecosystem services, but this relationship was complex and remained contentious (Benayas et al., 2009; Dodds et al., 2008). It is often assumed that biodiversity plays a key role in the provision of a range of ecosystem services, with the implication that recovery of biodiversity should accelerate ecosystem services recovery (such as enhancement of agriculture production, soil erosion control service, biomass production, and increased soil organic carbon) (Fu et al., 2011; Song et al., 2014). However, the relationship varies in a more complicated manner because of ecological complexity, which calls for a systematic and in-depth research.

Grassland, the largest terrestrial ecosystem in China, covers more than $40 \%$ ( 3.93 million $\mathrm{km}^{2}$ ) of the total territory. About $78 \%$ of the grassland is found in arid and semiarid regions 
(Kang et al., 2007). Grassland is, therefore, critical in regional climate, biodiversity conservation, provision of ecosystem services and socioeconomic development (Wen et al., 2013; Wu et al., 2014; Zhao et al., 2015). These grasslands have suffered severe degradation from long-term overgrazing, cropland expansion and extensive use, and climate change (Liu et al., 2015; Wu et al., 2010; Zeng et al., 2014). Sandstorms, desertification, and ecological refugees caused by environmental degradation have threatened animal husbandry, ecological security, and sustainable development in China (Jiang et al., 2006; Unkovich and Nan, 2008). Consequently, grassland restoration projects have been implemented to curtail degradation and to facilitate ecosystem recovery. Subsequently, grassland restoration has become a frontier and "hot theme" in ecological research and governmental policy.

Numerous studies have reported on changes in species diversity, soil carbon and nitrogen, vegetation, and soil properties during the restoration process (Shi et al., 2010; Zhang and Dong, 2010). However, few studies have systematically examined the effectiveness of restoration on biodiversity and ecosystem services recovery in grassland. A lack of scientific understanding of the effects of ecological restoration on biodiversity and ecosystem services limits their incorporation into grassland management and decision-making. Additionally, most studies of grassland restoration have been reported and published in the Chinese literature, so they are less accessible to the international community. To our knowledge, no meta-analysis has been performed to examine the effects of grassland restoration on biodiversity and ecosystem services across China. Given the high ecological and economic value of grassland, a comprehensive, evidence-based assessment of grassland restoration simultaneously examining biodiversity and ecosystem services could help inform future restoration efforts to achieve high effectiveness and sustainability.

In this study, we conducted a meta-analysis of the peerreviewed literature to quantitatively assess how grassland restoration affects biodiversity and ecosystem services in China. Our goal was to address four questions: (1) how much biodiversity and ecosystem services can be recovered through grassland restoration; (2) how recovery of biodiversity and ecosystem services differs geographically; (3) whether the effectiveness of biodiversity and ecosystem services recovery is affected by factors such as restoration approach and restoration age; and (4) whether biodiversity recovery correlates with ecosystem services recovery.

\section{Material and methods}

\subsection{Literature search and inclusion}

To gather quantitative evidence from the literature on effects of grassland restoration on biodiversity and ecosystem services, we systematically searched the ISI Web of Knowledge (http:// www.isiwebofknowledge.com) and the China National Knowledge Infrastructure (http://www.cnki.net/) on July 20, 2015, with no restriction on publication year, using the following search term combinations: (restor* OR recreat* ${ }^{*}$ OR rehabilitat* OR enhance* OR forest* OR reforest* OR afforest* OR recover* OR plant*) AND (ecosystem OR environment*) AND (biodiversity OR service* OR function* OR good*) AND (grassland OR steppe OR meadow OR lawn OR paddy). This resulted in a list of 2887 references. We then examined the titles, key-words, and abstracts of the references to assess their potential for meeting the selection criteria. We had three criteria for data inclusion:

(1) Articles must describe a grassland restoration project, reporting quantitative measures of variables related to biodiversity and/or ecosystem services under different restoration approaches and restoration ages.

(2) Studies used in the meta-analysis must present information comparing restored grassland with either degraded or reference (natural/undisturbed) grassland.

(3) Data reported in the selected studies must include sample size and standard deviation (or standard error/coefficient of variation), or this information could be extracted from the text and figures.

Qualitative review, modeling using empirical data, assessment based on RS and GIS, and studies without complete data for analysis were excluded from our selection. Finally, 70 studies were identified that met our criteria, and were used in the meta-analysis (see Supplementary data, Text A.1).

\subsection{Database building}

For each study, we extracted data on the Chinese province where the study was conducted, general properties of the study sites (longitude, latitude, and altitude), type of ecoregions, specific restoration actions, restoration age, variables of biodiversity and ecosystem services used to measure the impacts of grassland restoration (response variables). Separate databases were built for biodiversity and ecosystem services in which rows contained comparisons of the response variables between restored grassland and degraded or reference grassland. Each comparison was recorded as a separate row in the databases. Columns in the databases contained the properties of those comparisons (Supplementary data, Text B.1 and Table A.1).

We extracted data on variables relating to biodiversity, including density, abundance, richness, diversity index, and vegetation cover (Supplementary data, Text C.1). We categorized the broad biodiversity types as flora or vegetation, soil microorganism, invertebrate, and vertebrate. Response variables of ecosystem services were classified according to the four major categories proposed by MEA: supporting, regulating, provisioning, and cultural (Benayas et al., 2009; Meli et al., 2014; Millennium Ecosystem Assessment, 2005). The biophysical variables reported could be categorized as climate regulation, soil quality regulation, primary production, nutrient cycling, and forage and herbage; most of these were regulating and supporting ecosystem services. We assessed the ecosystem services by comparing response variables in restored and degraded or reference grassland. Only five comparisons from two studies reported on provisioning ecosystem services and none reported on cultural ecosystem services, so provisioning and cultural ecosystem services were excluded from the meta-analysis.

\subsection{Overview of the selected studies}

The 70 selected studies were mostly located in the northwestern and Tibet Plateau regions, which were dominated by temperate continental semi-arid monsoon climate and typical plateau continental climate. The mean annual precipitation of most of the study sites was less than $800 \mathrm{~mm}$.

The selected studies were conducted in nine provinces: Inner Mongolia (33 studies), Ningxia (9 studies), Gansu (8 studies), Jilin (6 studies), Qinghai (6 studies), Xizang (4 studies), Yunnan (2 studies), Sichuan (1 study), and Xinjiang (1 study) (Fig. 1). From the selected studies, we extracted 1884 comparisons: 625 comparisons from 49 studies for biodiversity, and 1259 comparisons from 54 studies for ecosystem services. To investigate the spatial characteristics of biodiversity and ecosystem services recovery, we grouped the study sites into four ecological domains: Northern arid and semi-arid (1000 comparisons, 34 studies), Northeastern humid and semi-humid (447 comparisons, 20 studies), Tibet Plateau (403 


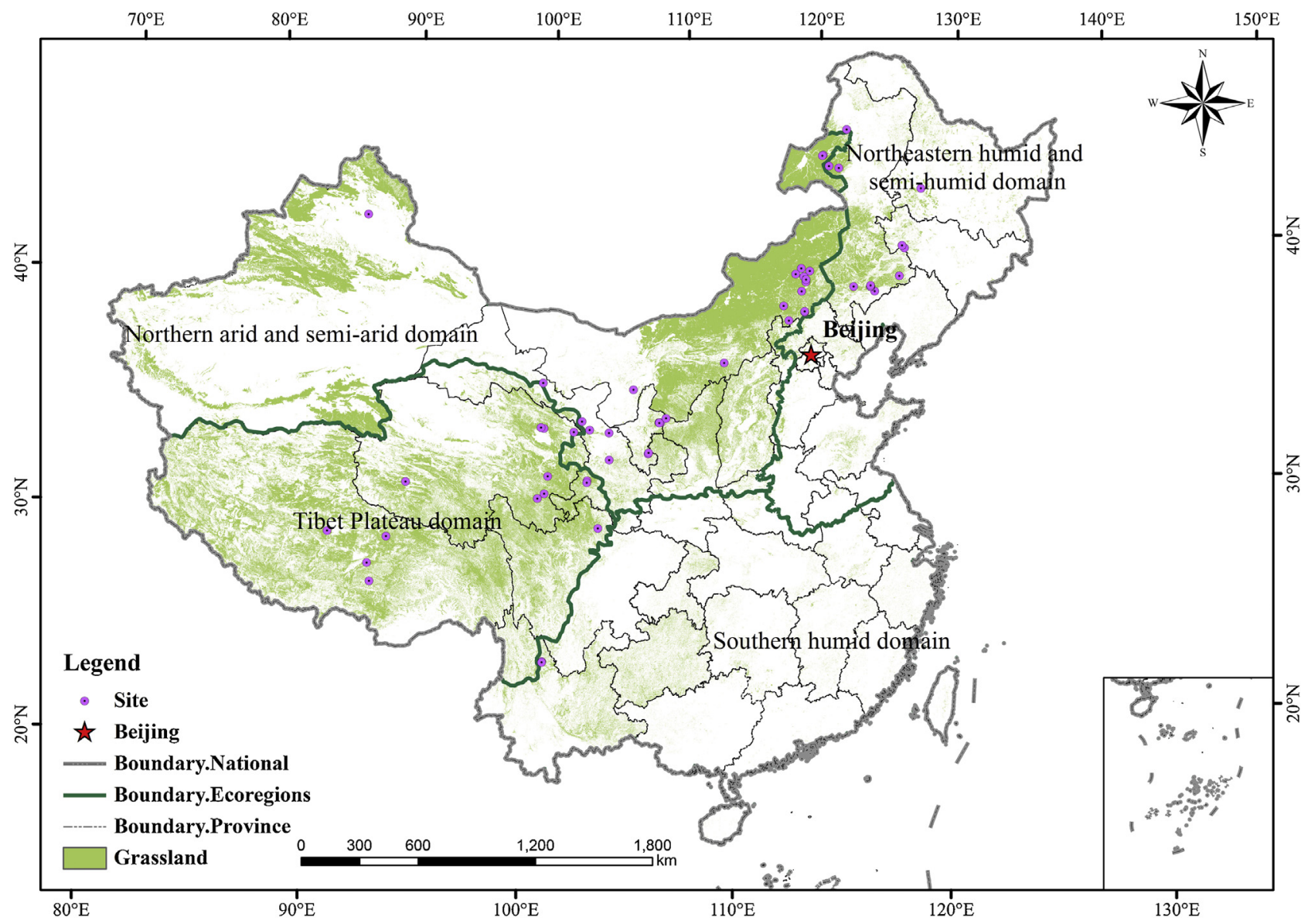

Fig. 1. National distribution of study sites in the meta-analysis.

comparisons, 14 studies), and Southern humid (34 comparisons, 2 studies), which is proposed by Xie et al. (2012) based on climate, topography and ecosystem characteristics. The studies reported either active (685 comparisons, 25 studies) or passive restoration approaches (1199 comparisons, 61 studies) (Table 1). Restoration ages reported in the studies ranged from several months to seventy years. The mean restoration age was ten years. Some of the selected studies did not report the exact time of grassland restoration, so we included 1744 comparisons from 67 studies for restoration age analysis.

\subsection{Response ratio calculation and statistical analysis}

To standardize and compare data from different study sites, we used response ratio (effect size) in the study, $\ln ($ Rest/Deg) and $\ln$
(Rest/Ref), where Rest, Deg, and Ref were the mean values of variables measured in the restored, degraded, and reference grasslands, respectively.

When calculating response ratios of biodiversity and ecosystem services, we assigned a positive symbol (+) for measurements which were interpreted as being positively related to biodiversity or ecosystem services. For example, it is often assumed that greater biomass is associated with a high level of supporting ecosystem services, called "primary production." However, in some cases, the response variables are not positively correlated with biodiversity or ecosystem services (for example, a greater amount of heavy metal concentration in the soil or higher values of soil bulk density are often assumed to be negatively related to the supply of ecosystem services). In those cases, we converted the symbol "+" into "-" to indicate negative relationships.

Table 1

Summary of the most commonly used approaches for grassland restoration.

\begin{tabular}{lll}
\hline Approach & Example & Reference \\
\hline Active & - Establishment of artificial grassland & (Yuan et al., 2012; Wang et al., 2013) \\
& - Improvement measures (hallowing, reseeding, mixed-sowing, ploughing, fertilizer, irrigation) & (Zhang et al., 2013b) (Wang et al., 2015) \\
& - Introducing drought-enduring species & (Zeng et al., 2014) \\
& - Vegetation restoration & (Li et al., 2011a; Li et al., 2013a) \\
Passive & - Fencing/grazing exclusion & (Li et al., 2011b; Su et al., 2005) \\
& - Abandoned old fields & (Li, 2010)
\end{tabular}


Restored vs Degraded

Restored vs Reference

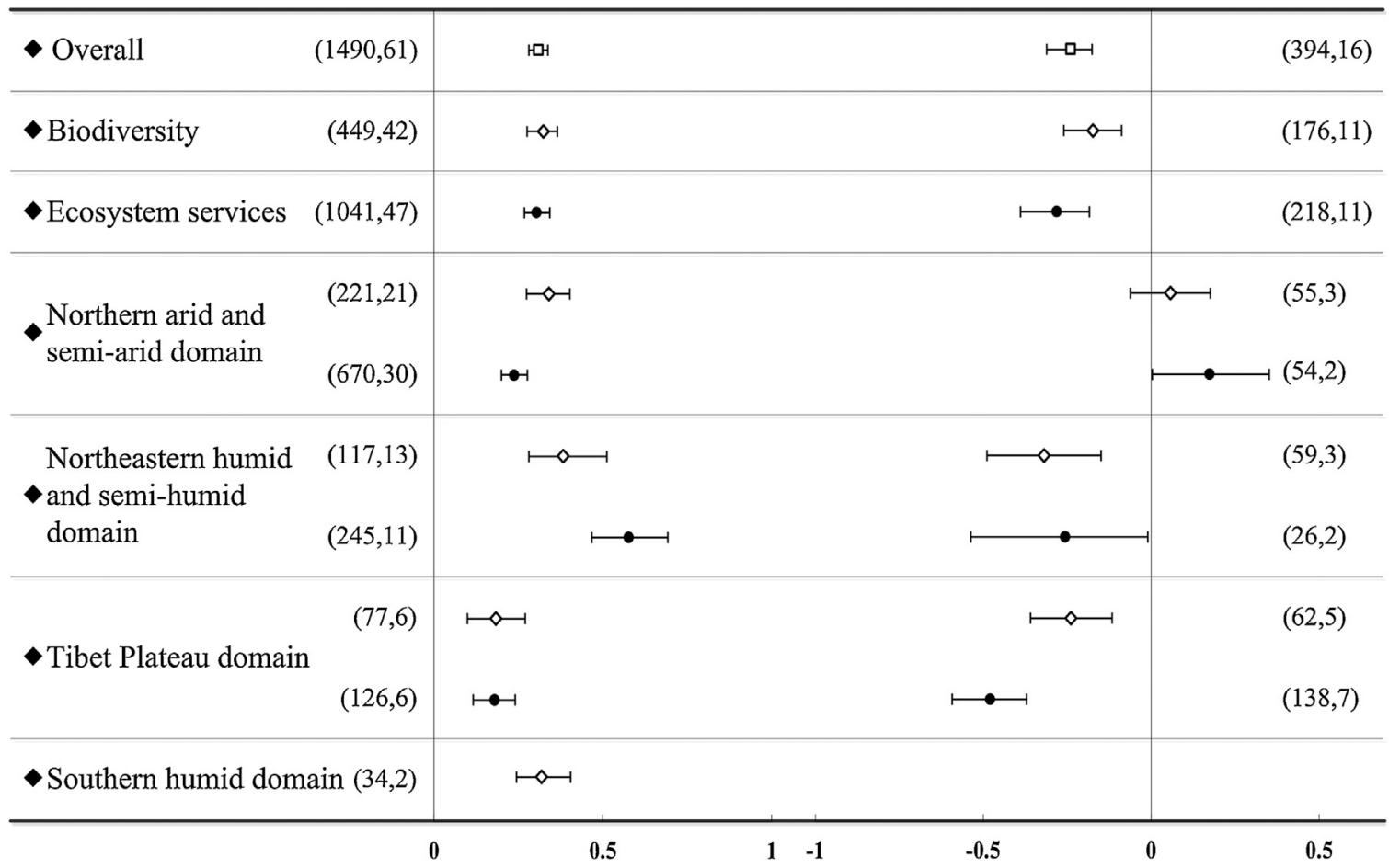

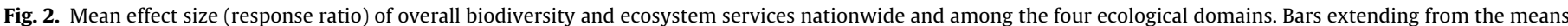
denoted bias-corrected $95 \%$ bootstrap-confidence intervals. Numbers in parentheses indicated the number of comparisons and number of studies.

A categorical, random-effect model was used to calculate mean response ratios assuming random variation among comparisons; 95\% confidence intervals were calculated from the mean response ratios using bootstrapping with 999 iterations (Rosenberg et al., 2000). Values of measurement in restored ecosystem were considered significantly different from that of degraded or reference ecosystem if their 95\% confidence intervals of the response ratios did not include zero.

We used Rosenthal's fail-safe number to check for publication bias (Rosenberg, 2005; Rosenthal, 1979). Rosenthal proposed that a meta-analysis could be considered resistant to the publication bias if the fail-safe number is larger than $5 k+10$, where $k$ is the number of comparisons used in the analysis. In our study, we obtained a fail-safe number of 84209516.5 for restored vs. degraded grassland, and 1191815.5 for restored vs. reference grassland. Both of these were larger than $5 \mathrm{k}+10$ ( 7460 for the former and 1980 for the latter). Therefore, the results of our meta-analysis were reliable. We also checked for publication bias using funnel plots (Supplementary data, Text B.1) (Li et al., 2013b).

To check for the possible pseudo-replication problem, we calculated the mean response ratios for a reduced dataset and the whole dataset. Consequently, the two types of response ratios had no significant differences, and both of their bias-corrected 95\% bootstrap-confidence intervals were overlapped (Supplementary data, Text B.1). Hence, it was reliable to include all the data in our study.

To investigate the effects of different restoration approaches, we used Mann-Whitney $U$ test to examine biodiversity and ecosystem services response ratios. We performed Spearman's rank correlation to determine whether the restoration outcomes were affected by restoration age, and whether biodiversity recovery correlated with ecosystem services recovery. We selected 25 of the 70 studies to conduct the relationship analysis, because these 25 studies reported data on both of biodiversity and ecosystem services. We treated the 25 studies as 25 independent samples, and pooled the relating response ratios of biodiversity or ecosystem services to generate an overall response ratio for each study. This resulted in 25 pooled response ratios for either biodiversity or ecosystem services in comparison of restored grassland and degraded grassland. We did not analyze the comparison of restored grassland and reference grassland, since the relevant data came from only five studies. Response ratio calculation was performed using MetaWin 2.0 (Rosenberg et al., 2000). Statistical analysis and plotting were conducted using SPSS 19.0 and EXCEL 2007 (SPSS, 2010).

\section{Results}

\subsection{General effects of grassland restoration}

Overall, the levels of biodiversity and ecosystem services were $30.98 \%$ higher in the restored grassland than in the degraded grassland, but were $23.92 \%$ lower than the reference grassland (Fig. 2). Grassland restoration enhanced biodiversity by $32.44 \%$ and increased the supply of ecosystem services by $30.43 \%$. As compared with the reference grassland, there was still a disparity in biodiversity and ecosystem services of the restored grassland. The biodiversity and ecosystem services were $17.34 \%$ and $28.07 \%$ lower, respectively, than the reference state.

All grasslands with restoration intervention in the four ecological domains showed greater biodiversity and ecosystem services than the degraded grassland. The Northeastern humid and semihumid domain had the largest increment of $38.29 \%$ for biodiversity and $57.77 \%$ for ecosystem services, followed by Northern arid and semi-arid domain (34.07\% for biodiversity and $23.74 \%$ for ecosystem services). Levels of biodiversity and ecosystem services in the Tibet Plateau domain were increased by $18.35 \%$ and $17.95 \%$, respectively. Biodiversity in the Southern humid domain was $31.84 \%$ higher in restored grassland than the degraded grassland, and there was no data for ecosystem services. 
(a)

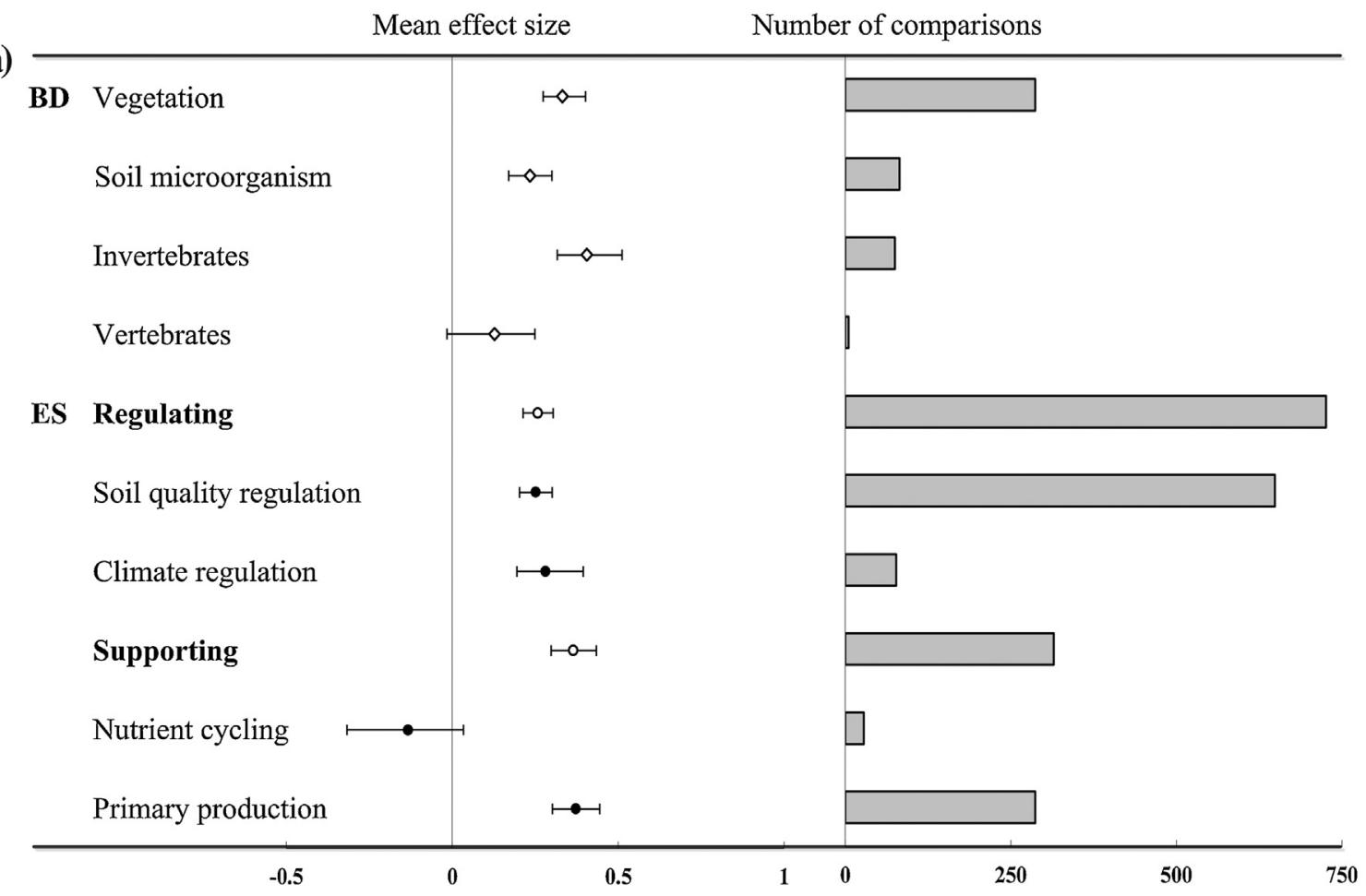

(b)

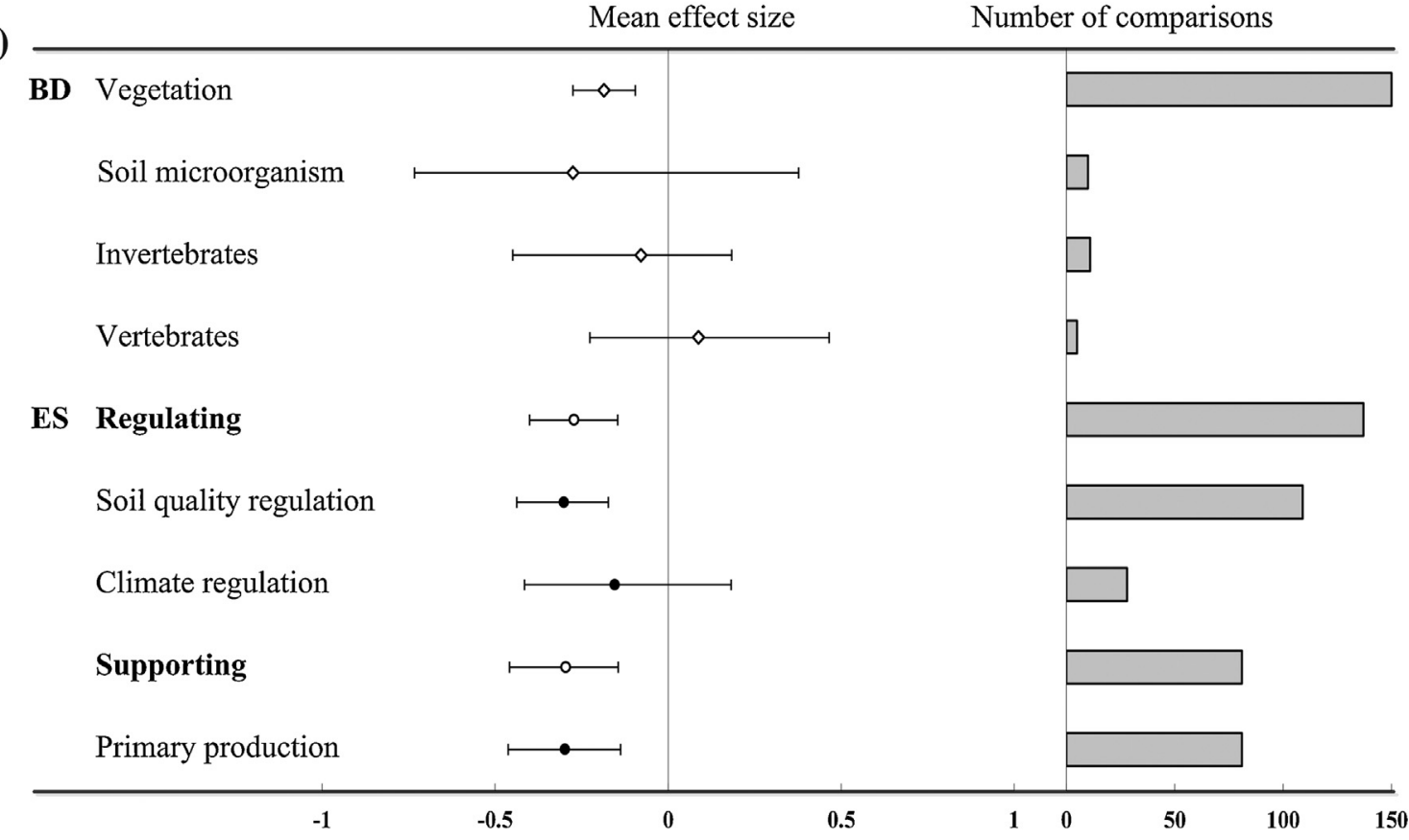

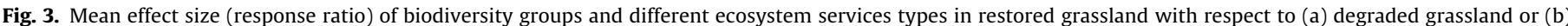

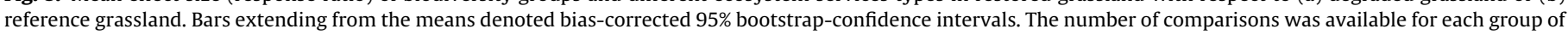
biodiversity and ecosystem services.

As for comparisons between restored grassland and reference grassland, biodiversity in the Northern arid and semi-arid domain appeared to have no significant difference, while ecosystem services showed a significant increase in restored grassland (17.39\%). Biodiversity in restored grassland of the Northeastern humid and semi-humid domain was $31.9 \%$ lower than the reference grassland, and ecosystem services were $25.6 \%$ lower than that of the reference state. Biodiversity and ecosystem services were $23.9 \%$ and $47.93 \%$ lower in restored grassland than in the reference grassland of the Tibet Plateau domain. For the Southern humid domain, both biodiversity and ecosystem services were not reported in the selected studies about comparisons on restored versus reference conditions. 


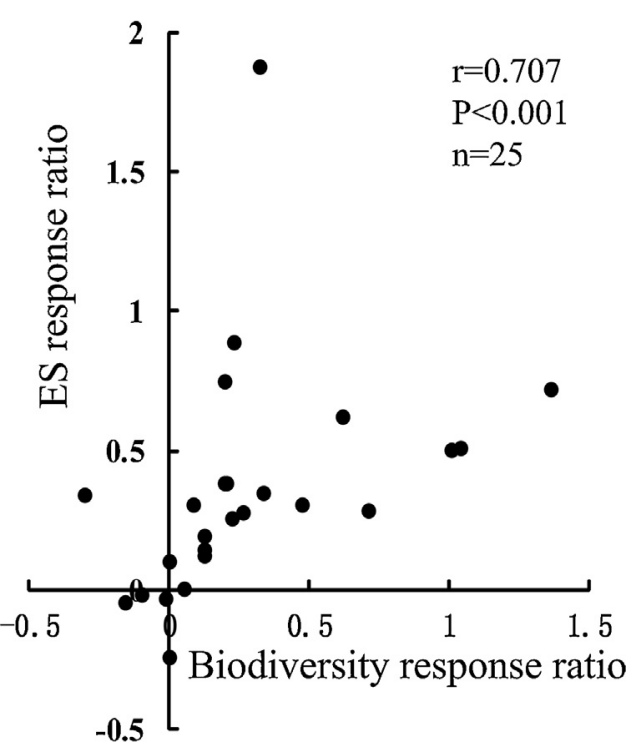

Fig. 4. Spearman rank correlations between biodiversity and ecosystem services in comparison of restored grassland and degraded grassland.

\subsection{Biodiversity and ecosystem services recovery}

Restoring the degraded grassland increased the biodiversity of vegetation (33.21\%), soil microorganisms (23.51\%), and invertebrates (40.58\%), but biodiversity of vertebrates did not significantly differ from that in degraded grassland (Fig. 3). Restored and reference grassland showed similar biodiversity of soil microorganisms, invertebrates, and vertebrates, with the exception of vegetation, which was $18.51 \%$ lower in restored grassland than in the reference grassland.

Grassland restoration also enhanced a range of ecosystem services. The supply of regulating ecosystem services increased by an average of $25.78 \%$, with the following increases for specific ecosystem services types: soil quality regulation (25.17\%) and climate regulation (28.13\%). Supply of supporting ecosystem services was $36.5 \%$ higher in restored grassland than in the degraded grassland, with the difference of $37.29 \%$ for primary production, while nutrient cycling did not differ significantly between restored and degraded grassland. Compared to reference grassland, restored grassland appeared to have a lower supply of regulating ecosystem services (27.19\%) and supporting ecosystem services (29.57\%), among which soil quality regulation and primary production was $30.14 \%$ and $29.81 \%$ lower than the reference state. Climate regulation in restored grassland was not significantly different from that in reference grassland. There was no data for nutrient cycling in comparison of restored and reference grassland.

Biodiversity and ecosystem services response ratios were positively correlated in comparison of restored grassland and degraded grassland, indicating that biodiversity recovery was positively correlated with ecosystem services recovery (Fig. 4). To investigate the regional variation of the relationships, we further examined the differences of the relationships among the four ecological domains. The results indicated a positive relationship between biodiversity recovery and ecosystem services recovery both in the Northeastern humid and semi-humid domain $(\mathrm{r}=0.9, \mathrm{p}<0.05, \mathrm{n}=5)$ and Northern arid and semi-arid domain $(r=0.618, p<0.05, n=16)$. Results in the Tibet Plateau domain did not show a statistically significant correlation between biodiversity recovery and ecosystem services recovery $(r=0.4, p=0.6, n=4)$. Moreover, there was no data for the Southern humid domain.
Table 2

Effects of restoration approach on biodiversity and ecosystem services in comparison of restored grassland and degraded grassland.

\begin{tabular}{|c|c|c|c|c|}
\hline & \multicolumn{2}{|c|}{ Biodiversity } & \multicolumn{2}{|c|}{ Ecosystem services } \\
\hline & Active & Passive & Active & Passive \\
\hline Pooled $\ln R$ & 0.3801 & 0.2873 & 0.3849 & 0.2587 \\
\hline Mann-Whitney U & \multicolumn{2}{|c|}{19872} & \multicolumn{2}{|c|}{110373} \\
\hline $\mathrm{p}$ & \multicolumn{2}{|c|}{0.002} & \multicolumn{2}{|c|}{0.006} \\
\hline $\mathrm{n}$ & 177 & 272 & 363 & 678 \\
\hline mean $\ln R$ & 0.380 & 0.298 & 0.397 & 0.260 \\
\hline$S D$ of $\ln R$ & 0.478 & 0.556 & 0.752 & 0.590 \\
\hline
\end{tabular}

\subsection{Effects of restoration approach and age on restoration} outcomes

Mann-Whitney $U$ test showed that active and passive restoration approaches were associated with significant differences in biodiversity and ecosystem services in restored grassland compared to degraded grassland (Table 2). We pooled multiple measurements of active approach and passive approach to generate one averaged response ratio (pooled $\ln R$ ) using MetaWin. The pooled lnRs were similar to the means of response ratios under either approach. Both were larger in the active approaches than that in the passive ones. Biodiversity and ecosystem services showed similar differences.

Restoration age was not detected to have statistically significant correlation with biodiversity $\ln R(r=-0.051, \mathrm{p}=0.308, \mathrm{n}=405)$ or ecosystem services $\ln R(r=0.007, p=0.820, n=961)$ using Spearman's rank test.

\section{Discussion}

\subsection{Impacts of grassland restoration on biodiversity and ecosystem services}

Our study provided quantitative evidence that grassland restoration exerted significant impacts on biodiversity and supply of ecosystem services. Restoration efforts in grassland are likely to lead to large increases in biodiversity and ecosystem services. Field observations and experimental studies have generally been conducted in small-scale plots, which are different from the combination of a range of scales in our meta-analysis study. However, meta-analysis is often restricted by the lack of relevant information. In our study, we did not analyze the provisioning and cultural ecosystem services for the limited number of appropriate studies. Furthermore, meta-analysis offers a powerful statistical method that integrates and standardizes results, which are coincident or conflicted, and makes it possible to compare studies conducted in different sites (Stewart, 2010; Vilà et al., 2011). Accordingly, studies with unwanted results (such as water shortage and reduction of native species for introducing non-native trees in arid and semiarid regions) can also be considered in the meta-analysis to gain a general assessment of the ecological restoration effects (Cao et al., 2009). Based on that, our meta-analysis results focus on revealing general patterns of the impacts of grassland restoration despite the differences comparing with observations and experimental studies. When studies conducted on different scales were combined, ecological restoration in degraded grassland showed great positive impacts on biodiversity and ecosystem services. The levels of biodiversity and supply of ecosystem services reported in the present study were increased by $30.98 \%$ comparing with the degraded state, which indicated the effectiveness of implemented measures. Moreover, the increment of biodiversity and ecosystem services showed decline trend among northeastern, northern, and Tibet Plateau regions. The general patterns of impacts of grassland restoration 
can contribute to choosing restoration priorities and appropriate approaches.

\subsection{Recovery differences among ecological domains, restoration ages, and approaches}

Magnitude and direction of the impacts of grassland restoration on biodiversity and ecosystem services could vary among regions, restoration ages, and restoration approaches (Li et al., 2013a; Yuan et al., 2012; Zhang et al., 2013b). Our results showed that grassland restoration did not uniformly increase the levels of biodiversity and ecosystem services across the four ecological domains. The Northeastern humid and semi-humid domain showed the largest increment for biodiversity and ecosystem services, followed by Northern arid and semi-arid domain and Southern humid domain. The Tibet Plateau domain showed less increment than the other three ecological domains. These differences are attributed to numerous factors, such as grassland ecosystem types, topographical and climatic conditions, and management systems (Jing et al., 2013; Mayer et al., 2009; Yan and Lu, 2015). China's rich grassland resources, including alpine meadow, tundra, and steppe, are located in different bio-climatic regions and are composed of different communities and ecosystems (Li et al., 2013b), which can inevitably lead to an inconsistent response to grassland restoration.

Careful consideration needs to be given to the interpretation of the results about restoration age. Our statistical results did not reflect a significant correlation between restoration age and biodiversity or ecosystem services recovery in grassland, which was consistent with other meta-analyses conducted in different ecosystems (Barral et al., 2015; Meli et al., 2014). Nevertheless, experimental studies conducted in specific sites usually report positive correlations (Pei et al., 2008; Zuo et al., 2009). As mentioned above, meta-analysis is used to integrate findings among different studies, and to identify general large-scale patterns across species and geographic regions. In addition, there are several context factors that may lead to temporally varying recovery of biodiversity and ecosystem services, including duration of the restoration process, times that a restoration action is repeated, and the initial conditions prior to restoration. Unfortunately, most of the studies included in the meta-analysis did not report such data. Further research should examine those contextual factors in greater detail.

Restoration age was found to be statistically non-significant based on our dataset, which could not be interpreted as it had no significant effect on restoration outcomes such as biodiversity and ecosystem service enhancement on the ground. One possible explanation is the complex and usually nonlinear responses of ecosystem restoration processes to time (Hu et al., 2016). In our dataset, the restoration ages varied widely from several months to decades across large geographical ranges, which caused diverse and usually inconsistent restoration effects on restoration ages from different geographic locations. Therefore, we need to be very careful with cause-effect attributions concerning restoration age based on simple statistical methods.

The results showed that both active and passive restoration could increase the levels of biodiversity and ecosystem services in degraded grassland. The response ratios of active approaches were larger than passive ones, as active approaches may be expected to yield quicker and more dramatic short-term results than the passive approaches (Liu et al., 2014). Nonetheless, we cannot conclude that active approaches were more effective in restoring the degraded ecosystems, as well as enhancing biodiversity and ecosystem services. Given that natural recovery in many ecosystems can take decades, active restoration projects are becoming increasingly common to accelerate the recovery process (Zhang et al., 2013b). There is considerable debate about whether active restoration is always necessary, and to what extent artificial intervention is needed to facilitate the recovery (Jiang et al., 2006; Prach and Hobbs, 2008). As for restoring the degraded grassland, Li et al. (2013b) put forward the concepts of alternative stable states and transition framework. In the framework, grassland degradation falls into reversible or irreversible categories according to whether or not the abiotic conditions have been excessively modified. Restoration measures appropriate for reversible grassland degradation are designed to reduce the grazing intensity and to bring the stock population to a sustainable level. For irreversibly degraded grassland, drastic anthropogenic intervention measures (such as artificial seeding, the introduction of pioneer species, and implementation of windbreaks) are required (Li et al., 2013c). Consequently, effective measures for grassland restoration must focus on the extent and mechanisms of degradation, the response of ecosystem component, the general context of degraded ecosystems, the resilience of restored ecosystems, and their long-term self-sustainability. Maximizing opportunities for natural processes is advocated in degraded grassland, especially when the environmental conditions are not very extreme, considering expenditures of labor and budget, the limited resources, and the sustainability of the restored ecosystems (Prach and Hobbs, 2008).

\subsection{Restoration for sustainable grassland management}

Ecological restoration is an effective strategy for reversing deteriorated grassland and increasing biodiversity and provision of ecosystem services. In the meantime, conflicts can arise over the recovery process (Spake et al., 2015). As shown in our results, grassland restoration was partially successful in achieving reference conditions, as the biodiversity was $17.34 \%$ lower than the reference state and ecosystem services were $28.07 \%$ lower than that of reference grassland. Therefore, large-scale evaluations may indicate a failure to fully restore the biodiversity or ecosystem services to the reference state, despite the fact that individual restoration projects conducted in different regions are reported to be successful (Bullock et al., 2011; Fagan et al., 2008). Furthermore, limited funding of restoration projects will often constrain recovery processes and decisions (Holl and Aide, 2011). Analyses of whether or not the benefits from ecological restoration outweigh the costs are scarce (Bullock et al., 2011). A focus on restoration of biodiversity and ecosystem services will require more emphasis on the benefits of stakeholders, one of the goals of the widely implemented Payment for Ecosystem Services (PES) (Farley et al., 2010). Trade-offs among biodiversity conservation, maintaining of ecosystem services, and extensive land use are always popular topics of restoration research.

Considering the positive relationship shown in our study, biodiversity and ecosystem services may provide complementary approaches for ecological restoration and ecosystem management. Our results showed that response ratios of biodiversity were positively correlated with those of ecosystem services in comparison of restored grassland and degraded grassland. Essentially, restoration efforts to increase one should enhance the other. An increase in biodiversity could be interpreted as an indication that the structure and functioning, as well as the relevant ecosystem services of the grasslands, are recovering from the degraded state. This positive relationship may indicate a "win-win" situation for biodiversity and ecosystem services recovery in the degraded grassland. It is a promising scheme to combine biodiversity conservation and ecosystem services maintenance into grassland management and ecological restoration projects. Our results also showed a variation of the relationship between biodiversity and ecosystem services recovery among different ecological domains. This may contribute to investigating the spatial correlations between biodiversity and ecosystem services, and optimizing the synergy between them. This 
is urgently needed not only for grassland management, but also for the restoration of a wide range of degraded ecosystems.

As suggested by our results, recovery of degraded grassland following ecological restoration as currently practiced often cannot reach the reference state, but ecological restoration can effectively improve the levels of biodiversity and ecosystem services. In addition, given that very small proportions of some natural or undisturbed ecosystems remain, grassland conservation and ecological restoration will continue to be necessary management tools for sustainable utilization of grassland resources. Furthermore, considering the marked variability in environmental conditions, restoration efforts for deteriorated grasslands must vary by regions and degree of degradation. For example, the Northeastern humid and semi-humid domain had good conditions of air temperature and precipitation, which is advantageous for enhancement of biodiversity and ecosystem services. Spontaneous regeneration of the grassland is more cost-effective than the active measures. With regard to the Northern arid and semi-arid domain and Tibet Plateau domain, which have poor environmental conditions, active approaches may be necessary to facilitate the recovery process. Moreover, near-natural restoration can be an effective means of grassland management, by taking more account of the recovery of biodiversity, ecosystem functioning, and services than structure recovery, which has been the focus of conventional restoration projects. Restoration projects should be designed with a reference, and with consideration of possible response of ecosystem structure and functions to management actions. Finally, it is also very helpful if a standard protocol is established for ecological restoration planning, design, implementation, and performance assessment based on core criteria of common concerns and optional ones suited to specific geographical contexts. With this protocol, easier comparisons can be made across large spatiotemporal scales.

\section{Conclusions}

While there are many experimental studies and qualitative reviews about the effects of grassland restoration on biodiversity and ecosystem services, our study is the first extensively quantitative meta-analysis of these effects in China. Our results suggest that grassland restoration can be effective in enhancing biodiversity and supply of ecosystem services, while the increases in biodiversity and ecosystem services can vary spatially in large geographical extents. Response ratios of biodiversity were positively related to the response ratios of ecosystem services. Restoration of biodiversity and ecosystem services differed significantly between active approaches and passive ones. The general significant effects of restoration age at the site scale could be blurred at the regional scale; this is likely because of larger spatiotemporal variation of restoration treatments, and the related responses from biodiversity and ecosystem services that are usually represented as inconsistent. These findings can facilitate priority setting and treatment methods during restoration planning and assessment for high efficiency, effectiveness, and sustainability.

Furthermore, the impacts of grassland restoration on biodiversity and ecosystem services vary in relation to multiple factors (initial conditions prior to restoration, degradation mechanisms, topographical and climatic characteristics, management actions, and duration of the restoration process). The links between biodiversity recovery and ecosystem services recovery remain largely unexplored. More complete data and process-based synthetic research efforts are needed to move beyond these preliminary and brief analyses to assess the synergy among ecological restoration, ecosystem services, and human well-being. We emphasize that caution is warranted when making decisions about grassland restoration, and that long-term sustainable development of grassland could be achieved only when taking into account multiple factors, in addition to achievement of biodiversity and ecosystem services enhancement.

\section{Acknowledgments}

We thank all the authors who shared their original data for developing this study. This research was supported by the Chinese Academy of Sciences (KFJ-EW-STS-021-03).

\section{Appendix A. Supplementary data}

Supplementary data associated with this article can be found, in the online version, at http://dx.doi.org/10.1016/j.ecoleng.2016.06. 082 .

\section{References}

Barral, M.P., Benayas, J.M.R., Meli, P., Maceira, N.O., 2015. Quantifying the impacts of ecological restoration on biodiversity and ecosystem services in agroecosystems: a global meta-analysis. Agric. Ecosyst. Environ. 202, 223-231.

Benayas, J.M.R., Newton, A.C., Diaz, A., Bullock, J.M., 2009. Enhancement of biodiversity and ecosystem services by ecological restoration: a meta-analysis. Science 325, 1121-1124.

Bullock, J.M., Aronson, J., Newton, A.C., Pywell, R.F., Benayas, J.M.R., 2011. Restoration of ecosystem services and biodiversity: conflicts and opportunities. Trends Ecol. Evol. 26, 541-549.

Butchart, S.H.M., Walpole, M., Collen, B., Van Strien, A., Scharlemann, J.P.W., Almond, R.E.A., Baillie, J.E.M., Bomhard, B., Brown, C., Bruno, J., Carpenter, K.E., Carr, G.M., Chanson, J., Chenery, A.M., Csirke, J., Davidson, N.C., Dentener, F., Foster, M., Galli, A., Galloway, J.N., Genovesi, P., Gregory, R.D., Hockings, M., Kapos, V., Lamarque, J.F., Leverington, F., Loh, J., McGeoch, M.A., McRae, L., Minasyan, A., Morcillo, M.H., Oldfield, T.E.E., Pauly, D., Quader, S., Revenga, C., Sauer, J.R., Skolnik, B., Spear, D., Stanwell-Smith, D., Stuart, S.N., Symes, A., Tierney, M., Tyrrell, T.D., Vié, J.C., Watson, R., 2010. Global biodiversity: indicators of recent declines. Science 328, 1164-1168.

Calmon, M., Brancalion, P.H.S., Paese, A., Aronson, J., Castro, P., Silva, S.C., Rodrigues, R.R., 2011. Emerging threats and opportunities for large-Scale ecological restoration in the Atlantic forest of Brazil. Restor. Ecol. 19, 154-158.

Cao, S.X., Chen, L., Yu, X.X., 2009. Impact of China's Grain for Green Project on the landscape of vulnerable arid and semi-arid agricultural regions: a case study in northern Shaanxi Province. J. Appl. Ecol. 46, 536-543.

Dodds, W.K., Wilson, K.C., Rehmeier, R.L., Knight, G.L., Wiggam, S., Falke, J.A., Dalgleish, H.J., Bertrand, K.N., 2008. Comparing ecosystem goods and services provided by restored and native lands. Bioscience 58, 837-845.

Fagan, K.C., Pywell, R.F., Bullock, J.M., Marrs, R.H., 2008. Do restored calcareous grasslands on former arable fields resemble ancient targets? The effect of time, methods and environment on outcomes. J. Appl. Ecol. 45, 1293-1303.

Farley, J., Aquino, A., Daniels, A., Moulaert, A., Lee, D., Krause, A., 2010. Global mechanisms for sustaining and enhancing PES schemes. Ecol. Econ. 69, 2075-2084.

Fu, B.J., Liu, Y., Lü, Y.H., He, C.S., Zeng, Y., Wu, B.F., 2011. Assessing the soil erosion control service of ecosystems change in the Loess Plateau of China. Ecol. Complexity 8, 284-293.

Holl, K.D., Aide, T.M., 2011. When and where to actively restore ecosystems? For. Ecol. Manage. 261, 1558-1563.

Hu, Z.M., Li, S.G., Guo, Q., Niu, S.L., He, N.P., Li, L.H., Yu, G.R., 2016. A synthesis of the effect of grazing exclusion on carbon dynamics in grasslands in China. Glob. Change Biol. 22, 1385-1393.

Jiang, G.M., Han, X.G., Wu, J.G., 2006. Restoration and management of the Inner Mongolia Grassland requires a sustainable strategy. Ambio 35, 269-270.

Jing, Z.B., Cheng, J.M., Chen, A., 2013. Assessment of vegetative ecological characteristics and the succession process during three decades of grazing exclusion in a continental steppe grassland. Ecol. Eng. 57, 162-169.

Kang, L., Han, X.G., Zhang, Z.B., Sun, O.J., 2007. Grassland ecosystems in China: review of current knowledge and research advancement. Philos. Trans. R. Soc. B Biol. Sci. 362, 997-1008.

Li, F.R., Liu, J.L., Hua, W., Niu, R.X., Liu, Q.J., Liu, C.G., 2011a. Trophic group responses of ground arthropods to land-cover change and management disturbance. Acta Ecol. Sin. 31, 4169-4181 (in Chinese with English Abstract).

Li, Y.Q., Zhao, H.L., Zhao, X.Y., Zhang, T.H., Li, Y.L., Cui, J.Y., 2011b. Effects of grazing and livestock exclusion on soil physical and chemical properties in desertified sandy grassland Inner Mongolia, northern China. Environ. Earth Sci. 63, $771-783$.

Li, G., Wang, L.J., Li, Y.J., Qiao, J., Zhang, H.F., Song, X.L., Yang, D.L., 2013a. Effects of different vegetation restoration patterns on the diversity of soil nitrogen-fixing microbes in Hulunbeier sandy land, Inner Mongolia of North China. Chin. J. Appl. Ecol. 24, 1639-1646 (in Chinese with English Abstract).

Li, G.C., Wu, M.H., Yu, X.J., 2013b. Introduction to Meta-Analysis. Science Press, Beijing. 
Li, X.L., Gao, J., Brierley, G., Qiao, Y.M., Zhang, J., Yang, Y.W., 2013c. Rangeland degradation on the Qinghai-Tibet plateau: implications for rehabilitation. Land Degrad. Dev. 24, 72-80.

Li, W.J., 2010. Restoration Succession and Ecological Mechanism of Old-fields in Subalpine Meadow. Lanzhou University (in Chinese with English Abstract).

Liu, R.T., Zhu, F., An, H., Steinberger, Y., 2014. Effect of naturally vs manually managed restoration on ground-dwelling arthropod communities in a desertified region. Ecol. Eng. 73, 545-552.

Liu, S.L., Zhao, H.D., Su, X.K., Deng, L., Dong, S.K., Zhang, X., 2015. Spatio-temporal variability in rangeland conditions associated with climate change in the Altun Mountain National Nature Reserve on the Qinghai-Tibet Plateau over the past 15 years. Rangeland J. 37, 67-75.

Mayer, R., Kaufmann, R., Vorhauser, K., Erschbamer, B., 2009. Effects of grazing exclusion on species composition in high-altitude grasslands of the Central Alps. Basic Appl. Ecol. 10, 447-455.

Meli, P., Benayas, J.M.R., Balvanera, P., Ramos, M.M., 2014. Restoration enhances wetland biodiversity and ecosystem service supply, but results are context dependent: a meta-analysis. PLoS One 9, e93507.

Millennium Ecosystem Assessment, 2005. Ecosystems and Human Well-being: Synthesis. Island Press, Washington, DC.

Pei, S.F., Fu, H., Wan, C.G., 2008. Changes in soil properties and vegetation following exclosure and grazing in degraded Alxa desert steppe of Inner Mongolia, China. Agric. Ecosyst. Environ. 124, 33-39.

Prach, K., Hobbs, R.J., 2008. Spontaneous succession versus technical reclamation in the restoration of disturbed sites. Restor. Ecol. 16, 363-366.

Rosenberg, M.S., Adams, D.C., Gurevitch, J., 2000. MetaWin: Statistical Software for Meta-Analysis. Sinauer Associates, Sunderland.

Rosenberg, M.S., 2005. The file-drawer problem revisited: a general weighted method for calculating fail-safe numbers in meta-analysis. Evolution 59 , 464-468.

Rosenthal, R., 1979. The file drawer problem and tolerance for null results. Psychol. Bull. 86, 638-641.

SPSS, I.B.M., (2010). SPSS for Windows (version 19) SPSS. Inc, Chicago, Illinois.

Sachs, J.D., Baillie, J.E.M., Sutherland, W.J., Armsworth, P.R., Ash, N., Beddington, J., Blackburn, T.M., Collen, B., Gardiner, B., Gaston, K.J., Godfray, H.C.J., Green, R.E., Harvey, P.H., House, B., Knapp, S., Kümpel, N.F., Macdonald, D.W., Mace, G.M., Mallet, J., Matthews, A., May, R.M., Petchey, O., Purvis, A., Roe, D., Safi, K., Turner, K., Walpole, M., Watson, R., Jones, K.E., 2009. Biodiversity conservation and the millennium development goals. Science 325, 1502-1503.

Shi, J.N., Chen, H., Wu, Y., Wu, N., 2010. Effects of livestock exclusion on vegetation and soil properties under two topographic habitats in an alpine meadow on the eastern Qinghai-Tibetan Plateau. Pol. J. Ecol. 58, 125-133.

Song, X.Z., Peng, C.H., Zhou, G.M., Jiang, H., Wang, W.F., 2014. Chinese Grain for Green Program led to highly increased soil organic carbon levels: a meta-analysis. Sci. Rep. 4, 4460.

Spake, R., Ezard, T.H.G., Martin, P.A., Newton, A.C., Doncaster, C.P., 2015. A meta-analysis of functional group responses to forest recovery outside of the tropics. Conserv. Biol. 29, 1695-1703.

Stewart, G., 2010. Meta-analysis in applied ecology. Biol. Lett. 6, 78-81.

Su, Y.Z., Li, Y.L., Cui, J.Y., Zhao, W.Z., 2005. Influences of continuous grazing and livestock exclusion on soil properties in a degraded sandy grassland, Inner Mongolia, northern China. Catena 59, 267-278.

Unkovich, M.J., Nan, Z.B., 2008. Problems and prospects of grassland agroecosystems in western China. Agric. Ecosyst. Environ. 124, 1-2.

Vilà, M., Espinar, J.L., Hejda, M., Hulme, P.E., Jarosik, V., Maron, J.L., Pergl, J., Schaffner, U., Sun, Y., Pysek, P., 2011. Ecological impacts of invasive alien plants: a meta-analysis of their effects on species, communities and ecosystems. Ecol. Lett. 14, 702-708.

Wade, M.R., Gurr, G.M., Wratten, S.D., 2008. Ecological restoration of farmland progress and prospects. Philos. Trans. R. Soc. B Biol. Sci. 363, 831-847.

Wang, C.T., Wang, G.X., Liu, W., Wang, Y., Hu, L., Ma, L., 2013. Effects of establishing an artificial grassland on vegetation characteristics and soil quality in a degraded meadow. Isr. J. Ecol. Evol. 59, 141-153.

Wang, J.F., Sha, Z.P., Guan, F.C., Zhang, Y.Y., Duan, J., 2015. Effects of transplanting on the grassland biomass and the plant diversity in the region of the Brahmaputra River in Tibet. J. China Agric. Univ. 20, 103-109 (in Chinese with English Abstract).

Wen, L., Dong, S.K., Li, Y.Y., Li, X.Y., Shi, J.J., Wang, Y.L., Liu, D.M., Ma, Y.S., 2013. Effect of degradation intensity on grassland ecosystem services in the alpine region of Qinghai-Tibetan Plateau, China. PLoS One 8, e58432.

Wu, G.L., Liu, Z.H., Zhang, L., Hu, T.M., Chen, J.M., 2010. Effects of artificial grassland establishment on soil nutrients and carbon properties in a black-soil-type degraded grassland. Plant Soil 333, 469-479.

Wu, X., Li, Z.S., Fu, B.J., Lu, F., Wang, D.B., Liu, H.F., Liu, G.H., 2014. Effects of grazing exclusion on soil carbon and nitrogen storage in semi-arid grassland in Inner Mongolia. China Chin. Geogr. Sci. 24, 479-487.

Xie, G.D., Zhang, C.S., Zhang, L.B., Su, D., Cao, S.Y., Leng, Y.F., Xiao, Y., 2012. China's county-scale ecological regionalization. J. Nat. Resour. 1, 016 (in Chinese with English Abstract).

Yan, Y., Lu, X.Y., 2015. Is grazing exclusion effective in restoring vegetation in degraded alpine grasslands in Tibet, China? PeerJ 3, e1020.

Yuan, J.Y., Ouyang, Z.Y., Zheng, H., Xu, W.H., 2012. Effects of different grassland restoration approaches on soil properties in the southeastern Horqin sandy land, northern China. Appl. Soil Ecol. 61, 34-39.

Zeng, Z.G., Bi, J.H., Li, S.R., Chen, S.Y., Pike, D.A., Gao, Y., Du, W.G., 2014. Effects of habitat alteration on lizard community and food web structure in a desert steppe ecosystem. Biol. Conserv. 179, 86-92.

Zhang, J.T., Dong, Y.R., 2010. Factors affecting species diversity of plant communities and the restoration process in the loess area of China. Ecol. Eng. $36,345-350$

Zhang, X., Hu, Y.L., Li, W.J., Liu, Y.J., Gu, X.L., Ji, X.Y., 2013b. Effects of different improvement measures on plant community and soil of typical pasture. Agric. Res. Arid Areas 31, 106-110 (in Chinese with English Abstract).

Zhao, H.D., Liu, S.L., Dong, S.K., Su, X.K., Wang, X.X., Wu, X.Y., Wu, L., Zhang, X., 2015. Analysis of vegetation change associated with human disturbance using MODIS data on the rangelands of the Qinghai-Tibet Plateau. Rangeland J. 37, 77-87.

Zuo, X.A., Zhao, H.L., Zhao, X.Y., Guo, Y.R., Zhang, T.H., Mao, W., Su, N., Feng, J., 2009 Species diversity of degraded vegetation in different age restorations in Horqin Sandy Land, Northern China. Acta Agrestia Sinica 18, 9-16 (in Chinese with English Abstract)

\section{Further reading}

Li, X.L., Perrylw, G., Brierley, G., Gao, J., Zhang, J., Yang, Y.W., 2013d. Restoration prospects for Heitutan degraded grassland in the Sanjiangyuan. J. Mt. Sci. 10, 687-698. 